\title{
Uncertainty estimation approach in catalytic fast pyrolysis of rice husk: Thermal degradation, kinetic and thermodynamic parameters study
}

\author{
Adrian Chun Minh Loy ${ }^{\mathrm{a}}$, Suzana Yusup ${ }^{\mathrm{a}, *}$, Bing Shen How ${ }^{\mathrm{b}}$, Chung Loong Yiin ${ }^{\mathrm{b}}$, \\ Bridgid Lai Fui Chin ${ }^{c}$, Mustakimah Muhammad ${ }^{\mathrm{a}}$, Yong Ling Gwee \\ ${ }^{a}$ National HiCoE Thermochemical Conversion of Biomass, Centre for Biofuel and Biochemical Research, Institute of Sustainable Building, Chemical Engineering \\ Department, Universiti Teknologi PETRONAS, Seri Iskandar, Perak 32610, Malaysia \\ ${ }^{\mathrm{b}}$ Department of Chemical Engineering, Faculty of Engineering, Computing and Science, Swinburne University of Technology, Jalan Simpang Tiga, 93350 Kuching, Sarawak, \\ Malaysia \\ ${ }^{\mathrm{c}}$ Department of Chemical Engineering, Faculty of Engineering and Science, Curtin University Malaysia, CDT 250, 98009 Miri Sarawak, Malaysia
}

\section{G R A P H I C A L A B S T R A C T}

Multiple non-linear regression and kinetic modelling on catalytic fast pyrolysis

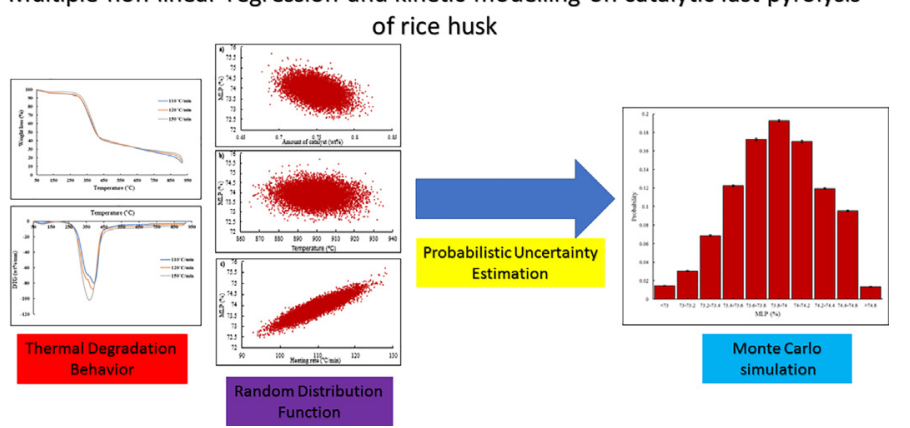

\section{A R T I C L E I N F O}

\section{Keywords:}

Rice husk

Catalytic fast pyrolysis

Kinetic study

Multi non-linear regression

Monte Carlo simulation

Uncertainty analysis

\begin{abstract}
A B S T R A C T
The aim of this study was to understand the influence of catalyst in thermal degradation behavior of rice husk $(\mathrm{RH})$ in catalytic fast pyrolysis (CFP) process. An iso-conversional Kissinger kinetic model was introduced into this study to understand the activation energy $\left(E_{A}\right)$, pre-exponential value $(A)$, Enthalpy $(\Delta H)$, Entropy $(\Delta S)$ and Gibb's energy $(\Delta G)$ of non-catalytic fast pyrolysis (NCFP) and CFP of RH. The study revealed that the addition of natural zeolite catalyst enhanced the rate of devolatilization and decomposition of $\mathrm{RH}$ associated with lowest $E_{A}$ value $(153.10 \mathrm{~kJ} / \mathrm{mol})$ compared to other NCFP and CFP using nickel catalyst. Lastly, an uncertainty estimation was applied on the best fit non-linear regression model (MNLR) to identify the explanatory variables. The finding showed that it had the highest probability to obtain $73.8-74.0 \%$ mass loss in CFP of rice husk using natural zeolite catalyst.
\end{abstract}

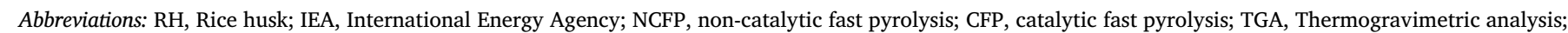

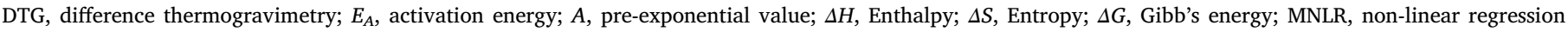

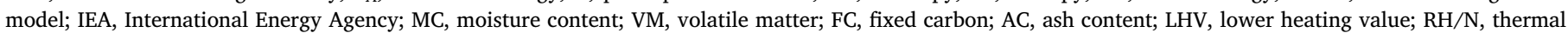

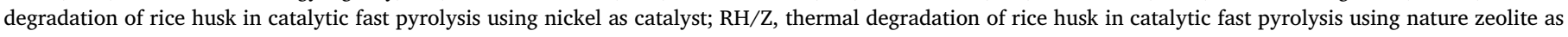
catalyst; VIF, variation inflation factor; D-W, Durbin Watson factor; MC, Monte Carlo

* Corresponding author.

E-mail address: drsuzana_yusuf@edu.utp.my (S. Yusup). 